\title{
Interferon-a adjuvant therapy decreases the recurrence of early clear cell renal cell carcinoma and improves the prognosis of Chinese patients
}

\author{
Hang Yin ${ }^{1, *}$, Cheng-Gong Liao ${ }^{1, *}$, Jian-Guo Huang ${ }^{1}$, Yong-Qiang Wang ${ }^{1}$, Zheng Li ${ }^{1}$, \\ Lu-Lu Fan ${ }^{1}$, Men-Long Qian ${ }^{1}$, Nao Wan ${ }^{1}$ and Ning Lu ${ }^{1}$ \\ ${ }^{1}$ Department of Oncology, General Hospital of Xinjiang Military Command, Urumqi 830000, P.R. China \\ "These authors contributed equally to this work
}

Correspondence to: Ning Lu, email: luning407@sina.com

Keywords: clear cell renal cell carcinoma, interferon- $a$, immunotherapy, recurrence

Received: November 16, $2016 \quad$ Accepted: June 02, $2017 \quad$ Published: June 19, 2017

Copyright: Yin et al. This is an open-access article distributed under the terms of the Creative Commons Attribution License 3.0 (CC BY 3.0 ), which permits unrestricted use, distribution, and reproduction in any medium, provided the original author and source are credited.

\section{ABSTRACT}

The survival time of patients with early clear cell renal cell carcinoma (ccRCC) is fairly long, but $\mathbf{2 0} \%$ to $\mathbf{3 0} \%$ of patients with localized tumors experience relapse, and the effect of IFN-a on survival has not been well studied in patients with early cCRCC. In this study, 208 patients with early ccRCC were treated with surgery, and 54 of the patients received IFN-a as adjuvant therapy. The remaining 115 patients were treated with surgery but not with IFN-a therapy. The primary endpoint was the recurrence rate, $20.37 \%(11 / 54)$ and $33.04 \%(38 / 115)$ in the IFN-a and surgeryonly group, respectively. The secondary endpoint was progression-free survival (PFS), which was 123.70 (95\% CI: 107.18-140.22) months for the IFN-a group, and 95.80 (95\% CI: 82.18-109.42) months for the non-IFN-a group; this difference was significant $(P<0.05)$. The main side effects were pyrexia $(61.11 \%)$, muscle pain $(24.07 \%)$, malaise $(9.26 \%)$, anorexia $(5.56 \%)$, hepatic dysfunction $(3.70 \%)$ and renal dysfunction (1.85\%). Moreover, a multivariate regression identified older age, higher BMI index and smoking as significant and independent predictors of decreased PFS $(P<0.05)$. Overall, IFN-a therapy significantly improved PFS in Chinese patients with early CCRCC and was an independent prognostic factor $(P<0.05)$. In conclusion, our study showed that adjuvant IFN-a therapy decreased the recurrence rate and prolonged PFS in patients with CCRCC. Thus, this treatment may help clinicians to select a better treatment modality and better predict survival in these patients.

\section{INTRODUCTION}

Renal cell carcinoma accounts for $2-3 \%$ of all new cancer cases [1], and ccRCC is the most common subtype accountings for $70-80 \%$ of all renal cancers. At present, the incidence of renal cell carcinoma among all cancers worldwide is growing $2.5 \%$ each year [2], and nephrectomy remains the preferred treatment for early ccRCC. However, $20 \%$ to $30 \%$ of patients with localized tumors experience relapse after surgical excision [3], and once metastasis occurs, the five-year survival rate is less than $10 \%$ [4]. However, effective adjuvant therapy for ccRCC after surgery has not yet been reported to successfully reduce the recurrence rate of ccRCC.

IFN- $\alpha$ is an immunotherapeutic agent generated by monocytes and macrophages, that has beneficial effects on human health in a variety of ways. For example, previous studies have shown that IFN- $\alpha$ activates the immune response [5], induces apoptosis [6], and directly inhibits the proliferation $[7,8]$ and differentiation of tumor cells [9]. It has also been proven effective as a multifunctional cytokine in pancreatic cancer cells [10]. 
Moreover, IFN- $\alpha$ has been used clinically and is recommended as a first-line systemic treatment for clear cell mRCC [11]. However, IFN- $\alpha$ has rarely been studied as a treatment for patients with ccRCC after surgery.

In this study, we collected clinical information from ccRCC patients. Patients were divided into two groups as a comparison. The final results were recurrence rate and the survival time of the two groups. Whether patients had IFN- $\alpha$ therapy was the only different factor between the two groups. A retrospective study was used to evaluate the effectiveness and safety of IFN- $\alpha$ in ccRCC. A followup survey was finished in June 2016. Survival curve and multivariate analysis were used for the prognosis of the two groups in ccRCC.

\section{RESULTS}

\section{Baseline demographics and treatment tumor response}

From May 1998 to June 2014, a total 208 ccRCC patients who underwent surgery at the General Hospital of Xinjiang Military Command were enrolled in this study. Thirty-nine patients were lost to follow-up in the study, and the remaining 169 patients included 122 males and 47 females. The mean maximum tumor diameter was $4.58 \pm 2.13 \mathrm{~cm}$ (range 1.3-14.0 cm). Tumor size was classified as less than $7 \mathrm{~cm}$ (T1) or more than $7 \mathrm{~cm}$ (T2). All tumors were limited to the kidneys. The median age of the patients was 60.89 years. In order to compare the baseline characteristics between the experimental group and the control group, these patients were stratified by age (every 20 years). The median body mass index (BMI) was $24.55 \pm 3.73$ and the BMI was stratified as follows: less than 18.5 (underweight), 18.5 to 24.99 (normal), 25 to 27.99 (overweight), 28 to 31.99 (obese) and more than 32 (morbidly obese). The Eastern Cooperative Oncology Group (ECOG) performance status ranged from $0(62.13 \%)$ to $1(37.87 \%)$. The postoperative status and the comparison of baseline characteristics between the experimental group and the control group are shown in Table 1 . These factors did not significantly differ between groups. After surgery, 54 patients had IFN- $\alpha$ therapy. The mean maximum tumor diameter of these patients was $5.17 \pm 2.11 \mathrm{~cm}$, their median age was 58.46 years, and their median BMI was $25.14 \pm 3.48$. The rates of recurrence in the experimental group are shown in Table 2. Specifically, an analysis of clinical information showed that the recurrence rate directly correlated with $\mathrm{BMI}$ and $\mathrm{T}$ stage (larger tumor) $(P<0.05)$. Therefore, the efficacy of IFN- $\alpha$ therapy may inversely correlate with BMI and T stage.

\section{Recurrence and death}

By December 2016, 49 patients were confirmed to have developed recurrence by CT scans or other relevant examinations, and 16 patients had died because of recurrence-related complications. The range of follow up duration was 4.67-216.54 months, and the median duration was 110.82 months. The primary endpoint recurrence rate in the experimental group was $20.37 \%$, which was significantly lower than that of the control group $(33.04 \%)(P<0.05)$. A univariate analysis was used to screen for potential prognostic factors, such as gender, age, BMI, ECOG performance status, tumor size and smoking status. The final follow-up results of the two groups are shown in Table 3. Specifically, recurrence directly correlated with a higher BMI, higher ECOG performance status, higher $\mathrm{T}$ stage and smoking $(P<0.05)$. Thus, these factors increase the recurrence risk and decrease the PFS of patients with ccRCC.

\section{Prognostic factors for survival}

Progression-free survival (PFS) was defined as the period from the date of surgery until the date of the last recurrence-free follow-up. The PFS of patients who had developed recurrence was defined as the period from the date of surgery until the date that the first disease recurrence was detected by medical imaging. The time from the initial surgery until death was defined as the OS. The results of a Kaplan-Meier analysis are presented in Figures 1-3.

Figure 1 shows that median PFS was 139.57 (95\% CI: 107.87-171.26) months in the experimental group and 126.19 (95\% CI: 82.18-189.99) months in the control group, and this difference was significant according to a log-rank test $(P=0.019)$.

The time at which patients had surgery differed between the groups. Specifically, therapy was more effective for patients who had surgery within 5 years, as indicated by the Kaplan-Meier analysis in Figure 2.

Figure 2 shows that the average PFS was 67.52 (95\% CI: 62.85-72.19) months in the experimental group and 51.35 (95\% CI: 44.99-57.71) months in the control group, and this difference was significant according to a log-rank test $(P=0.011)$

However, the Kaplan-Meier analysis showed that the OS did not significantly differ between the two groups, as shown in Figure 3. Specifically, the median OS was 178.79 (95\% CI: 166.73-192.85) months in the experimental group and 171.84 (95\% CI: 149.36-201.37) months in the control group, and this difference was not significant according to a log-rank test $(P=0.196)$.

The Cox proportional regression model is shown in Table 4. A multivariate analysis revealed that IFN- $\alpha$ therapy was a significant and an independent predictor of increased PFS, whereas smoking, older age and a higher BMI were identified as significant predictors of decreased PFS $(P<0.05)$. The factors shown in Table 4 may also decrease the efficacy of IFN- $\alpha$ therapy. However, additional factors may affect the PFS of these patients, and these factors remain to be identified in future studies. 
Table 1: Postoperative baseline demographic and clinical characteristics of Chinese patients with ccRCC

\begin{tabular}{|c|c|c|c|}
\hline Characteristics & $\begin{array}{c}\text { Number of patients in the experimental } \\
\text { group(Percentage) } N=54\end{array}$ & $\begin{array}{l}\text { Number of patients in the control } \\
\text { group (Percentage) } N=115\end{array}$ & $P$ value \\
\hline \multicolumn{4}{|l|}{ Gender } \\
\hline Male & $37(21.89 \%)$ & $85(50.30 \%)$ & \multirow[t]{2}{*}{0.466} \\
\hline Female & $17(10.06 \%)$ & $30(17.75 \%)$ & \\
\hline \multicolumn{4}{|l|}{ Age (Years) } \\
\hline $0-20$ & $0(0.00 \%)$ & $1(0.59 \%)$ & \multirow{5}{*}{0.251} \\
\hline $21-40$ & $3(1.78 \%)$ & $9(5.33 \%)$ & \\
\hline $41-60$ & $30(17.75 \%)$ & $45(26.63 \%)$ & \\
\hline $61-80$ & $19(11.24 \%)$ & 48 (28.40\%) & \\
\hline$>80$ & $2(1.18 \%)$ & $12(7.10 \%)$ & \\
\hline \multicolumn{4}{|l|}{ BMI $\left(\mathrm{kg} / \mathrm{m}^{2}\right)$} \\
\hline$\leq 18.5$ & $1(0.59 \%)$ & $12(7.10 \%)$ & \multirow{5}{*}{0.259} \\
\hline $18.5-24.99$ & $23(13.61 \%)$ & $52(30.77 \%)$ & \\
\hline $25-27.99$ & $20(11.83 \%)$ & $35(20.71 \%)$ & \\
\hline $28-31.99$ & $9(5.32 \%)$ & $12(7.10 \%)$ & \\
\hline$\geq 32$ & $1(0.59 \%)$ & $3(1.78 \%)$ & \\
\hline \multicolumn{4}{|c|}{ ECOG performance status } \\
\hline 0 & $34(20.12 \%)$ & $71(42.01 \%)$ & \multirow[t]{2}{*}{0.878} \\
\hline 1 & $20(11.83 \%)$ & $44(26.04 \%)$ & \\
\hline \multicolumn{4}{|l|}{ Smoking } \\
\hline YES & $18(10.65 \%)$ & $49(28.99 \%)$ & \multirow[t]{2}{*}{0.250} \\
\hline $\mathrm{NO}$ & $36(21.30 \%)$ & $66(39.05 \%)$ & \\
\hline \multicolumn{4}{|l|}{ Tumor size } \\
\hline $\mathrm{T} 1$ & $45(26.63 \%)$ & $106(62.72 \%)$ & \multirow[t]{2}{*}{0.082} \\
\hline $\mathrm{T} 2$ & $9(5.32 \%)$ & $9(5.32 \%)$ & \\
\hline
\end{tabular}

\section{Adverse events}

The statistical analysis of adverse events is shown in Table 5. Among the 54 patients who received IFN- $\alpha$ therapy, the main side effects included pyrexia $(61.11 \%)$, muscle pain (24.07\%), malaise $(9.26 \%)$, anorexia $(5.56 \%)$, hepatic dysfunction $(3.70 \%)$ and renal dysfunction $(1.85 \%)$. Symptomatic treatment was used when patients were not able to endure IFN- $\alpha$ therapy. All 54 patients finished at least one cycle of treatment, and none of the patients discontinued treatment due to adverse events.

\section{DISCUSSION}

Surgical resection remains an effective treatment for clinically localized ccRCC, and partial nephrectomy is proven and well-established to produce oncologic outcomes comparable to those of radical nephrectomy [12]. Moreover, a recent study showed that treatment with partial rather than radical nephrectomy was associated with improved survival among Medicare beneficiaries with early-stage kidney cancer [13]. However, $20 \%$ to $30 \%$ of patients with localized tumors experience relapse after surgical excision. Results from a retrospective analysis indicated that in a subset of patients, relapses occur more than 5 years after surgery for their primary RCC [14]. Our study examined a period exceeding 10 years, which might provide more powerful evidence.

In our study, we found that the recurrence rate was lower in the experimental group than in the control group. Kaplan-Meier analysis showed that the PFS differed between the two groups, especially for patients who had surgery within 5 years. However, interferon- $\alpha$ therapy after nephrectomy for early ccRCC patients had not been investigated for many years. Recent research showed that IFN- $\alpha$ therapy had synergistic immunotherapeutic effects and inhibited the proliferation of mouse RCC Renca cells in vitro and in vivo [15]. Specifically, the dose-effect curve demonstrated that the addition of $4,000 \mathrm{IU} / \mathrm{ml} \mathrm{IFN}-\alpha$ significantly inhibited the viability of the Renca cells 48 hours after administration. Recently, a study discovered that structurally modified curcumin could promote the apoptosis of human renal cell carcinoma by inhibiting STAT phosphorylation [16]. Thus, the STAT pathway might become an emerging oncogenic target in the setting of ccRCC, melanoma, and other forms of cancer [16]. Indeed, recent studies showed that human ccRCC cell lines 
Table 2: Recurrence and clinical features of IFN- $\alpha$ therapy for the Chinese patients with ccRCC

\begin{tabular}{|c|c|c|c|}
\hline Characteristics & $\begin{array}{l}\text { Number of recurrence-free } \\
\text { patients (Percentage) } N=43\end{array}$ & $\begin{array}{l}\text { Number patients who developed recurrence } \\
\text { (Percentage) } N=11\end{array}$ & $P$ value \\
\hline \multicolumn{4}{|l|}{ Gender } \\
\hline Male & $27(50.00 \%)$ & $10(18.52 \%)$ & \multirow{2}{*}{0.143} \\
\hline Female & $16(29.63 \%)$ & $1(1.85 \%)$ & \\
\hline \multicolumn{4}{|l|}{ Age (Years) } \\
\hline $0-20$ & $0(0.00 \%)$ & $0(0.00 \%)$ & \multirow{5}{*}{0.602} \\
\hline $21-40$ & $3(5.56 \%)$ & $0(0.00 \%)$ & \\
\hline $41-60$ & $24(44.44 \%)$ & $6(1.11 \%)$ & \\
\hline $61-80$ & $15(27.78 \%)$ & $4(7.41 \%)$ & \\
\hline$>80$ & $1(1.85 \%)$ & $1(1.85 \%)$ & \\
\hline \multicolumn{4}{|l|}{ BMI $\left(\mathrm{kg} / \mathrm{m}^{2}\right)$} \\
\hline$\leq 18.5$ & $1(1.85 \%)$ & $0(0.00 \%)$ & \multirow{5}{*}{0.029} \\
\hline $18.5-24.99$ & $14(25.93 \%)$ & $9(16.67 \%)$ & \\
\hline $25-27.99$ & $18(33.33 \%)$ & $2(3.70 \%)$ & \\
\hline $28-31.99$ & $9(16.67 \%)$ & $0(0.00 \%)$ & \\
\hline$\geq 32$ & $1(1.85 \%)$ & $0(0.00 \%)$ & \\
\hline \multicolumn{4}{|c|}{ ECOG performance status } \\
\hline 0 & $35(64.81 \%)$ & $7(12.96 \%)$ & \multirow{2}{*}{0.237} \\
\hline 1 & $8(14.81 \%)$ & $4(7.41 \%)$ & \\
\hline \multicolumn{4}{|l|}{ Tumor stage } \\
\hline $\mathrm{T} 1$ & $40(74.07 \%)$ & $5(9.26 \%)$ & \multirow{2}{*}{0.001} \\
\hline $\mathrm{T} 2$ & $3(5.56 \%)$ & $6(11.11 \%)$ & \\
\hline \multicolumn{4}{|l|}{ Smoking } \\
\hline YES & $12(22.22 \%)$ & $6(11.11 \%)$ & \multirow{2}{*}{0.150} \\
\hline NO & $31(57.41 \%)$ & $5(9.26 \%)$ & \\
\hline
\end{tabular}

were sensitive to Jak2-STAT pathway activity induced by dimethoxycurcumin [17], and recent clinical data suggested that the effects of drugs regularly used to treat RCC might elicit their anti-tumor effects via targeting of the STAT pathway. These findings suggest that the STAT pathway might be induced by biological factors in ccRCC. Moreover, IFN signaling was shown to regulate the STAT pathway in 2014 [18], which further supported evidence that the IFN pathway contributes to complex diseases. Theoretically, the relationship between the IFN pathway and STAT expression may prevent the recurrence of ccRCC.

Patients treated with IFN- $\alpha$ as adjuvant therapy after surgery was first reported in 2004 [19]. In that study, 88 patients with RCC had IFN- $\alpha$ therapy (5 million units once, 5 times a week, 4 weeks per cycle). The survival rates based on the pre-administration $\mathrm{pT}$ stage showed that the progression inversely correlated with $\mathrm{T}$ stage $(P=0.0966)$. Duration of IFN- $\alpha$ administration tended to positively correlate with long-term survival $(P=0.3765)$. In this study, conclusions were obtained based on beforeafter trials (BAT), but follow-up periods were relatively short, which may result in drastic changes in disease progression. The mean duration of follow-up in this study was 70.46 months, which limits the comparability of the two studies. Our study adopted a two-arm design, which was suitable for our disease and ensured accurate results. However, a disadvantage in this study was bias, including information bias and confounding bias. To decrease information bias, our research adopted several methods to obtain information from patients, such as telephone calls, e-mails, letters, and even visits to their families. We also adopted a multivariate analysis to decrease confounding bias. Some risk factors of ccRCC were computed by multivariate analysis to exclude interference.

In China, the dose of IFN- $\alpha$ in guidelines suggest gradient increments. Therefore, patients received 3 million units of IFN- $\alpha$ in the first week. 6 million units in the second week, 9 million units in the third week. In our study, most patients finished IFN- $\alpha$ therapy on time. However, 4 patients paused treatment because of grade 3 or worse side effect, but these patients finished treatment after recovering, and none of the 54 patients dropped out of the study. Table 2 shows recurrence after IFN- $\alpha$ therapy directly correlated with BMI and T stage (larger tumor). Thus, 3 million units may not be suitable for patients with a higher BMI and higher T stage (larger tumor), but this hypothesis requires further study. 
Table 3: Analysis of prognostic factors in Chinese patients with recurrent clear cell carcinoma

\begin{tabular}{|c|c|c|c|}
\hline Characteristics & $\begin{array}{c}\text { Number of recurrence-free } \\
\text { patients (Percentage) } N=120\end{array}$ & $\begin{array}{l}\text { Number of patients who developed } \\
\text { recurrence (Percentage) } N=49\end{array}$ & $P$ value \\
\hline \multicolumn{4}{|l|}{ Gender } \\
\hline Male & $82(48.52 \%)$ & $40(23.67 \%)$ & \multirow{2}{*}{0.080} \\
\hline Female & $38(22.48 \%)$ & $9(5.33 \%)$ & \\
\hline \multicolumn{4}{|l|}{ Age (Years) } \\
\hline $0-20$ & $1(0.59 \%)$ & $0(0.00 \%)$ & \multirow{5}{*}{0.562} \\
\hline $21-40$ & $10(5.92 \%)$ & $2(1.18 \%)$ & \\
\hline $41-60$ & $55(32.54 \%)$ & $20(11.83 \%)$ & \\
\hline $61-80$ & $46(27.21 \%)$ & $21(12.42 \%)$ & \\
\hline$>80$ & $8(4.73 \%)$ & $6(3.55 \%)$ & \\
\hline \multicolumn{4}{|l|}{ BMI $\left(\mathrm{kg} / \mathrm{m}^{2}\right)$} \\
\hline$\leq 18.5$ & $3(1.78 \%)$ & $10(5.92 \%)$ & \multirow{5}{*}{0.006} \\
\hline $18.5-24.99$ & $56(33.14 \%)$ & $20(11.83 \%)$ & \\
\hline $25-27.99$ & $41(24.26 \%)$ & $14(8.28 \%)$ & \\
\hline $28-31.99$ & $17(10.05 \%)$ & $4(2.37 \%)$ & \\
\hline$\geq 32$ & $3(1.78 \%)$ & $1(0.59 \%)$ & \\
\hline \multicolumn{4}{|l|}{ ECOG performance status } \\
\hline 0 & $85(50.30 \%)$ & $23(13.61 \%)$ & \multirow{2}{*}{0.003} \\
\hline 1 & $35(20.71 \%)$ & $26(15.38 \%)$ & \\
\hline \multicolumn{4}{|l|}{ Tumor stage } \\
\hline $\mathrm{T} 1$ & $112(66.27 \%)$ & $40(23.67 \%)$ & \multirow{2}{*}{0.044} \\
\hline $\mathrm{T} 2$ & $8(4.73 \%)$ & $9(5.39 \%)$ & \\
\hline \multicolumn{4}{|l|}{ Smoking } \\
\hline YES & $40(23.67 \%)$ & $27(15.98 \%)$ & \multirow{2}{*}{0.009} \\
\hline NO & $80(47.34 \%)$ & $22(13.02 \%)$ & \\
\hline
\end{tabular}

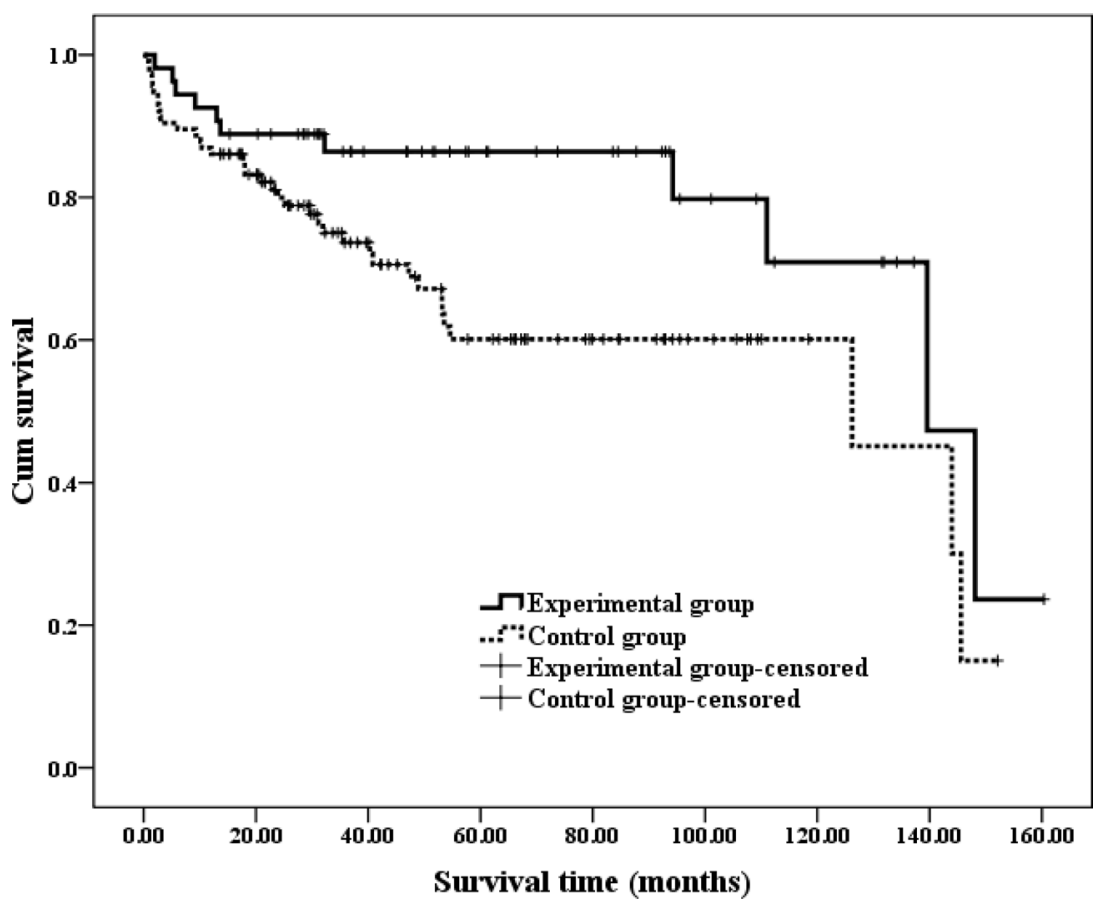

Figure 1: Kaplan-Meir estimates of PFS in different groups with ccRCC. The median time of PFS was 139.57 (95\% CI: 107.87-171.26) months in the experimental group and 126.19 (95\% CI: 82.18-189.99) months in the control group. 
A study showed that smoking and being overweight were risk factors of RCC. The incidence of RCC increased with exposure to tobacco. The risk of RCC also increased with increasing number of smoking years. The incidence of RCC had a gender difference that might be related to smoking [20]. In our study, smoking, older age and a higher BMI predicted decreased PFS. Thus, smoking and a higher BMI may be both risk and prognostic factors in ccRCC, whereas older age may only play a prognostic role.

In conclusion, IFN- $\alpha$-based immune therapy shows an effective extending of PFS in ccRCC patients, and may provide a new method to prevent the recurrence of ccRCC.

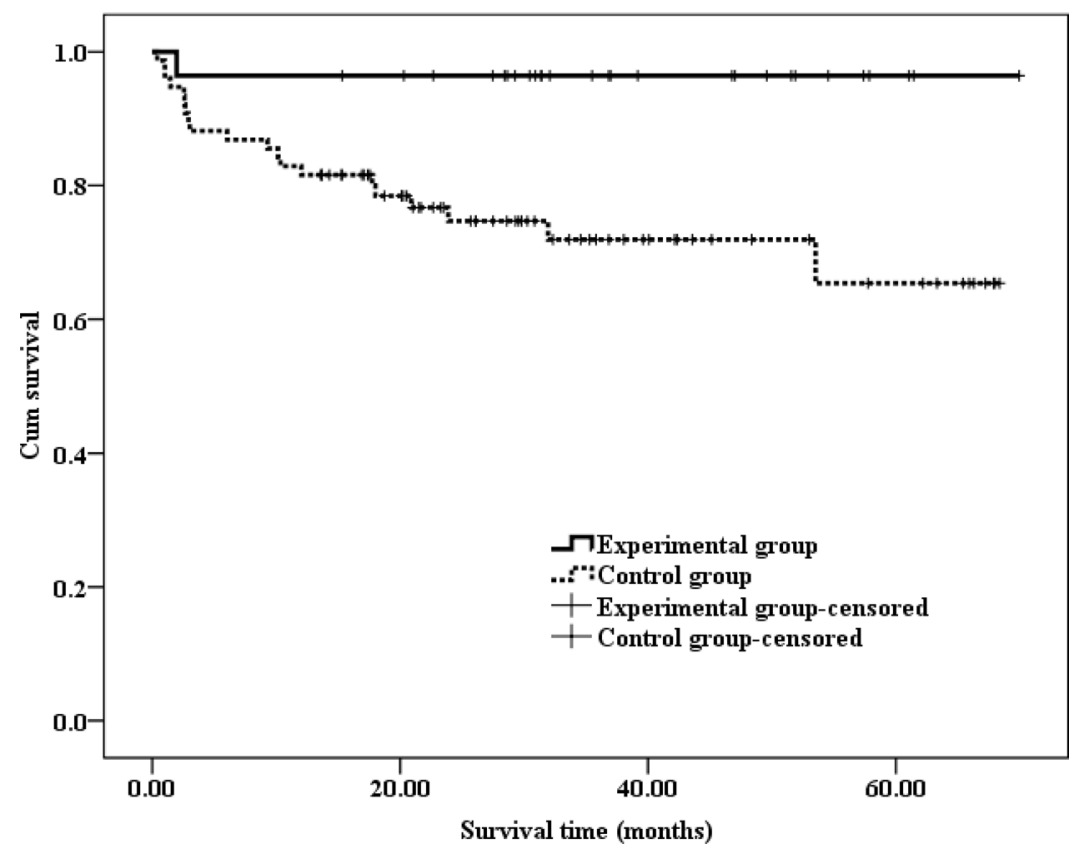

Figure 2: Kaplan-Meir estimates of 5-years PFS in patients with ccRCC. The average PFS was 67.52 (95\% CI: 62.85-72.19) months in the experimental group and 51.35 (95\% CI: 44.99-57.71) months in the control group.

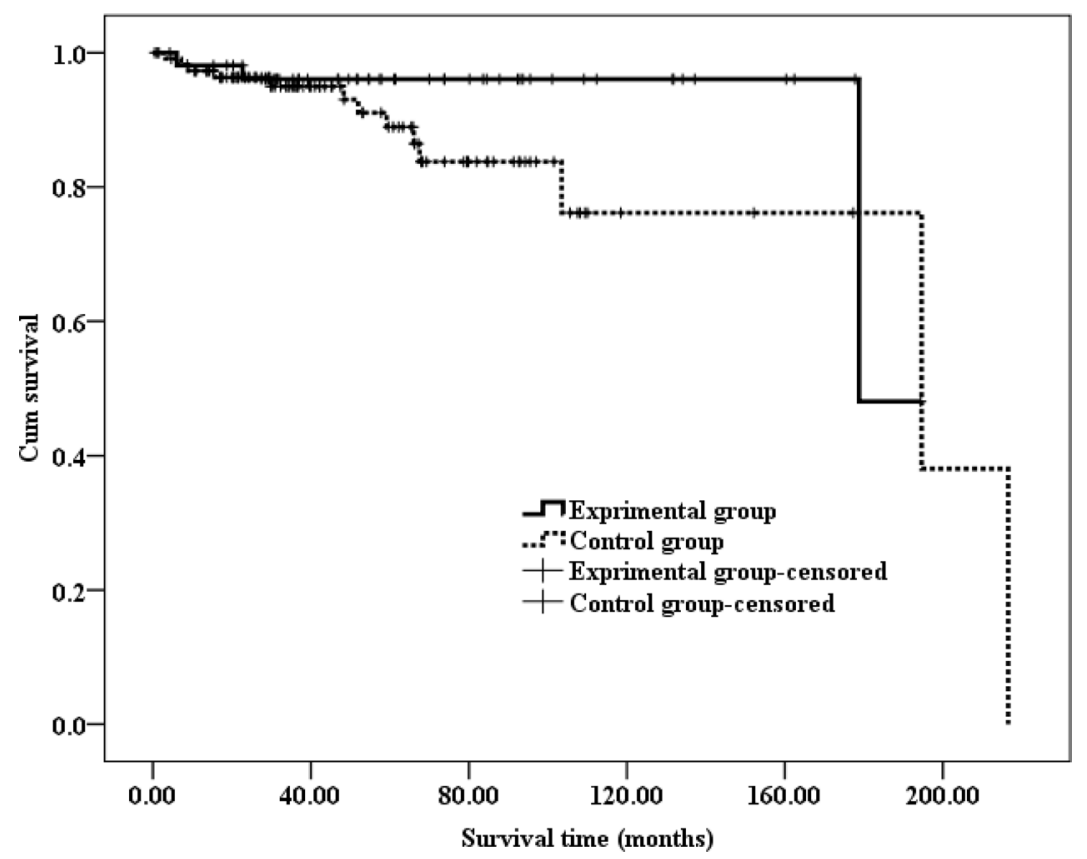

Figure 3: Kaplan-Meir estimates of OS in different groups with ccRCC. The median OS was 178.79 (95\% CI: 166.73-192.85) months in the experimental group and 171.84 (95\% CI: 149.36-201.37) months in the control group. 
Table 4: Cox proportional regression model for ccRCC

\begin{tabular}{ccc}
\hline Variable & Hazard Ratio (95\% CI) & P value \\
\hline IFN- $\alpha$ therapy & $0.567(0.378,0.851)$ & 0.006 \\
Smoking & $1.868(1.183,2.950)$ & 0.007 \\
Age group & $0.523(0.313,0.875)$ & 0.014 \\
BMI index & $1.743(1.187,2.560)$ & 0.005 \\
Diameter group & $1.284(0.859 .1 .920)$ & 0.223 \\
ECOG score & $0.790(0.457,1.367)$ & 0.400 \\
Gender & $0.852(0.549,1.321)$ & 0.474 \\
\hline
\end{tabular}

Table 5: Adverse events in the experimental group

\begin{tabular}{ccc}
\hline Variable & Any grade & $\geq$ Grade 3 \\
\hline Pyrexia & $33(61.11 \%)$ & $3(9.09 \%)$ \\
Muscle pain & $13(24.07 \%)$ & $1(7.69 \%)$ \\
Malaise & $5(9.26 \%)$ & $0(0.00 \%)$ \\
Anorexia & $3(5.56 \%)$ & $0(0.00 \%)$ \\
Hepatic dysfunction & $2(3.70 \%)$ & $0(0.00 \%)$ \\
Renal dysfunction & $1(1.85 \%)$ & $0(0.00 \%)$ \\
Total cases & $54(100 \%)$ & $4(7.41 \%)$ \\
\hline
\end{tabular}

\section{MATERIALS AND METHODS}

\section{Inclusion criteria}

This retrospective study was approved by the review board of the General Hospital of Xinjiang Military Command. In total, 208 patients with early ccRCC who provided informed consent were screened between July 1998 and June 2014. The patients had at least one measurable lesion (over $10 \mathrm{~mm}$ in largest diameter), and baseline computed tomography (CT) scans were available for each patient. The $\mathrm{CT}$ scans were reviewed independently by at least two senior radiologists. Other relevant examinations included MRI, SPECT and PET/ CT to confirm the tumor. All patients were pathologically diagnosed to ensure that the tumor was clear cell renal cell carcinoma. To be eligible for the study, patients were at least 18 years of age. The patients were free of other comorbidities and additional tumors. Their hepatic and renal functions were normal, and all tumors were limited to the kidneys. After screening, 39 patients were censored from this study, and the last follow-up for the remaining 169 patients was in December 2016. Specifically, 54 patients with early ccRCC treated with surgery who received IFN- $\alpha$ constituted the experimental group, and the remaining 115 patients, who were treated with surgery but not with IFN- $\alpha$ therapy, were enrolled in the control group.

\section{Treatment and follow-up}

Patients had IFN- $\alpha$ therapy after surgery as treatment. 54 patients provided informed consent and received one dose of 3 million units IFN- $\alpha$, three times per week, in four-weeks cycles. Treatment was continued for at least four cycles but stopped once unacceptable toxicity occurred. Once unexpected side effects, such as high fever, hepatic dysfunction or renal dysfunction exceeding grade 3 occurred, the dose of IFN- $\alpha$ was reduced or treatment was paused until the patients recovered.

Patients in the experimental group were followed up monthly during IFN- $\alpha$ treatment using complete blood count, serum electrolytes, liver function and renal function tests. After completing or stopping treatment, these patients were followed up every 3 months, the same as the control group. Assessments included CT scans or other relevant medical imaging examinations, physical examinations and routine laboratory tests.

\section{Outcomes and assessments}

The primary end point was the recurrence rate, and the secondary end point was PFS (the period from the date of surgery until the date of the first medical imaging examination that indicated disease progression). Multivariate analysis of recurrence included prognostic factors, such as age, gender, tumor size, IFN- $\alpha$ therapy, smoking, ECOG performance status and BMI. The safety outcomes were the incidence of adverse events associated with the first administration of IFN- $\alpha$ (especially grade 3 or worse adverse events).

\section{Statistical analysis}

The sample size in our study was computed by professional statisticians using the following formula: 
$n=2 \overline{\mathrm{p}} \overline{\mathrm{q}}\left(\mathrm{Z}_{\alpha}+\mathrm{Z}_{\beta}\right)^{2} /\left(\mathrm{p}_{1}-\mathrm{p}_{0}\right)^{2}$, which yielded a sample size of 153.93. Our cohort was larger than this computed number, which ensures the credibility of our results. All statistical analyses were performed using SPSS software, version 17. Continuous variables, such as PFS and OS, are reported as medians and interquartile ranges. Categorical data, such as age, gender, tumor size, smoking and BMI, are presented as proportions. The follow-up duration was calculated using the Kaplan-Meier method, and the OS and PFS were estimated using the Kaplan-Meier method with a Rothman $95 \%$ CI and compared across groups using the log-rank test. The Cox proportional hazards model was used to evaluate the prognostic value of the investigated parameters. All $P$ values were two-sided and were considered significant at $<0.05$.

\section{CONFLICTS OF INTEREST}

The authors indicate no potential conflicts of interest.

\section{REFERENCES}

1. Abe H, Kamai T. Recent advances in the treatment of metastatic renal cell carcinoma. Int J Urol. 2013; 20:944-955.

2. Pellicano F, Mukherjee L, Holyoake TL. Concise review: cancer cells escape from oncogene addiction: understanding the mechanisms behind treatment failure for more effective targeting. Stem cells. 2014; 32:1373-1379.

3. Eggener SE, Yossepowitch O, Pettus JA, Snyder ME, Motzer RJ, Russo P. Renal cell carcinoma recurrence after nephrectomy for localized disease: predicting survival from time of recurrence. J Clin Oncol. 2006; 24:3101-3106.

4. Krause DS, Van Etten RA. Tyrosine kinases as targets for cancer therapy. N Engl J Med. 2005; 353:172-187.

5. Guenterberg KD, Lesinski GB, Mundy-Bosse BL, Karpa VI, Jaime-Ramirez AC, Wei L, Carson WE 3rd. Enhanced anti-tumor activity of interferon-alpha in SOCS1-deficient mice is mediated by CD4(+) and CD8(+) T cells. Cancer Immunol Immunother. 2011; 60:1281-1288.

6. Maeda S, Wada H, Naito Y, Nagano H, Simmons S, Kagawa Y, Naito A, Kikuta J, Ishii T, Tomimaru Y, Hama N, Kawamoto K, Kobayashi S, et al. Interferon-alpha acts on the $\mathrm{S} / \mathrm{G} 2 / \mathrm{M}$ phases to induce apoptosis in the G1 phase of an IFNAR2-expressing hepatocellular carcinoma cell line. J Biol Chem. 2014; 289:23786-23795.

7. Liu X, Lu J, He ML, Li Z, Zhang B, Zhou LH, Li Q, Li G, Wang L, Tian WD, Peng Y, Li XP. Antitumor effects of interferon-alpha on cell growth and metastasis in human nasopharyngeal carcinoma. Current cancer drug targets. 2012; 12:561-570.

8. Motylewska E, Lawnicka H, Kowalewicz-Kulbat M, Sicinska P, Niedziela A, Melen-Mucha G, Stepien H. Interferon alpha and rapamycin inhibit the growth of pheochromocytoma PC12 line in vitro. Endokrynol Pol. $2013 ; 64: 368-374$.
9. Wolf B, Schwarzer A, Cote AL, Hampton TH, Schwaab T, Huarte E, Tomlinson CR, Gui J, Fisher JL, Fadul CE, Hamilton JW, Ernstoff MS. Gene expression profile of peripheral blood lymphocytes from renal cell carcinoma patients treated with IL-2, interferon-alpha and dendritic cell vaccine. PloS one. 2012; 7:e50221.

10. Booy S, van Eijck CH, Dogan F, van Koetsveld PM, Hofland LJ. Influence of type-I Interferon receptor expression level on the response to type-I Interferons in human pancreatic cancer cells. J Cell Mol Med. 2014; 18:492-502.

11. Ljungberg B, Bensalah $\mathrm{K}$, Canfield S, Dabestani S, Hofmann F, Hora M, Kuczyk MA, Lam T, Marconi L, Merseburger AS, Mulders P, Powles T, Staehler M, et al. EAU guidelines on renal cell carcinoma: 2014 update. Eur Urol. 2015; 67:913-924.

12. Lee HJ, Liss MA, Derweesh IH. Outcomes of partial nephrectomy for clinical $\mathrm{T} 1 \mathrm{~b}$ and $\mathrm{T} 2$ renal tumors. Curr Opin Uro. 2014; 24:448-452.

13. Tan HJ, Norton EC, Ye Z, Hafez KS, Gore JL, Miller DC. Long-term survival following partial vs radical nephrectomy among older patients with early-stage kidney cancer. JAMA. 2012; 307:1629-1635.

14. Stewart SB, Thompson RH, Psutka SP, Cheville JC, Lohse CM, Boorjian SA, Leibovich BC. Evaluation of the National Comprehensive Cancer Network and American Urological Association renal cell carcinoma surveillance guidelines. J Clin Oncol. 2014; 32:4059-4065.

15. Chen S, Liang L, Wang Y, Diao J, Zhao C, Chen G, He Y, Luo C, Wu X, Zhang Y. Synergistic immunotherapeutic effects of Lycium barbarum polysaccharide and interferonalpha $2 b$ on the murine Renca renal cell carcinoma cell line in vitro and in vivo. Mol Med Rep. 2015; 12:6727-6737.

16. Bill MA, Nicholas C, Mace TA, Etter JP, Li C, Schwartz EB, Fuchs JR, Young GS, Lin L, Lin J, He L, Phelps M, Li PK, et al. Structurally modified curcumin analogs inhibit STAT3 phosphorylation and promote apoptosis of human renal cell carcinoma and melanoma cell lines. PloS one. 2012; 7:e40724.

17. Lee JW, Hong HM, Kwon DD, Pae HO, Jeong HJ. Dimethoxycurcumin, a structural analogue of curcumin, induces apoptosis in human renal carcinoma caki cells through the production of reactive oxygen species, the release of cytochrome $\mathrm{C}$, and the activation of caspase-3. Korean J Urol. 2010; 51:870-878.

18. Lagor WR, Fields DW, Bauer RC, Crawford A, Abt MC, Artis D, Wherry EJ, Rader DJ. Genetic manipulation of the ApoF/Stat2 locus supports an important role for type I interferon signaling in atherosclerosis. Atherosclerosis. $2014 ; 233: 234-241$.

19. Gotoh A, Shirakawa T, Hinata N, Wada Y, Hara I, Fujisawa M, Kawabata G, Okada H, Arakawa S, Kamidono S. Long-term outcome of postoperative interferon-alpha adjuvant therapy for non-metastatic renal cell carcinoma. Int J Urol. 2004; 11:257-263. 
20. Kroeger N, Xie W, Lee JL, Bjarnason GA, Knox JJ, Mackenzie MJ, Wood L, Srinivas S, Vaishamayan UN, Rha SY, Pal SK, Yuasa T, Donskov F, et al. Metastatic nonclear cell renal cell carcinoma treated with targeted therapy agents: characterization of survival outcome and application of the International mRCC Database Consortium criteria. Cancer. 2013; 119:2999-3006. 